\section{Method for Simultaneous RNA and DNA Isolation from Biopsy Material, Culture Cells, Plants and Bacteria}

\section{BioTechniques 22:88-90 (January 1997)}

The analysis of RNA and DNA in clinical biopsy material for diagnostic and research purposes has become more and more important. Currently available methods and kits are used to focus on the extraction of only one kind of nucleic acid, but since the amount of biopsy material is often limited, a method for the simultaneous isolation of both kinds of nucleic acids from one sample is desirable. In contrast to DNA, RNA is rapidly degraded, and biopsy material often cannot be immediately preserved during the surgery process. We found that it is necessary to totally break up the tissue to get RNA from the inner parts of the biopsy where RNA degradation has not yet occurred, as physiologic conditions have been retained in this region for a longer time. Some tissues, especially skin, are very difficult to break up, and conventional methods (e.g., guanidine thiocyanate) (2) yield too little intact RNA (20-30 ng/mg tissue) of total RNA with an average size of $0.2-0.4 \mathrm{~kb}$ because of degradation, or the DNA is fragmented into small pieces because of harsh grinding procedures. For these reasons, we developed this method, which allows us to isolate simultaneously high-molecular-weight DNA and RNA in sufficient amounts from fresh and cryo-preserved material.

Punch biopsies $(4 \mathrm{~mm})$ or small spindles of skin (50-200 mg) were cut up with a scalpel in $1 \mathrm{~mL}$ of $7 \mathrm{M}$ urea, $2 \%$ sodium dodecyl sulfate (SDS), 5 $\mathrm{mM}$ EDTA (pH 8.0) and transferred into a Dounce apparatus (Dumas, Zurich, Switzerland). One milliliter of phenol/chloroform $(1: 1, \mathrm{vol} / \mathrm{vol})$ was added, and the tissue was ground by hand with a glass pestle. The liquified material was transferred to a microcentrifuge tube, and the remaining uncrushed material was broken up with another $1 \mathrm{~mL}$ of $7 \mathrm{M}$ urea, 2\% SDS, 5 $\mathrm{mM}$ EDTA and phenol/chloroform.
(All inorganic and organic reagents and solvents were purchased from Fluka, Buchs, Switzerland.) The dissolved material was centrifuged for $10 \mathrm{~min}$ at full speed in an Eppendorf microcentrifuge, and the upper phase was extracted with chloroform. The upper phase was transferred to another microcentrifuge tube containing an equal volume of isopropanol (propanol-2). The vial was gently inverted until the threads of the high-molecular-weight DNA had contracted into a small clump, which easily could be removed. The remaining solution of the DNA precipitation was kept for $1 \mathrm{~h}$ at $-20^{\circ} \mathrm{C}$ and centrifuged for $10 \mathrm{~min}$ at top speed in an Eppendorf microcentrifuge. The pellet containing total RNA and lowermolecular-weight DNA was dissolved in TE $(10 \mathrm{mM}$ Tris-HCl, $1 \mathrm{mM}$ EDTA, $\mathrm{pH}$ 8.0) and, this preparation can be used for reverse transcription polymerase chain reaction (RT-PCR) to produce a product, which spans several exons.
To obtain pure RNA, the solution containing the dissolved nucleic acids is loaded on a $\mathrm{CsCl}$ cushion (1), centrifuged in an SW40 rotor (Beckman Instruments, Fullerton, CA, USA) overnight at $35000 \mathrm{rpm}$, and the RNA pellet on the bottom of the polyallomer tube (Beckman Instruments) is dissolved in TE. Because of its lower specific weight, the remaining DNA will be retained by the $\mathrm{CsCl}$ cushion, and it can be recovered from the layer above the $\mathrm{CsCl}$ cushion in case the cell number should be so low that DNA clumps do not form (see above). Fresh and 2-3-years-old cryo-preserved biopsy material yielded 200-400 ng genomic DNA and 50-100 ng total RNA per 1 $\mathrm{mg}$ tissue, respectively. This yield is approximately 10 times higher than that of the conventional methods (e.g., guanidine thiocyanate). The centrifugation step also removes RNA molecules smaller than $0.3 \mathrm{~kb}$ (Figure 1A, lane 2), which are not useful for RT-PCR and cDNA cloning. RNA prepared in this

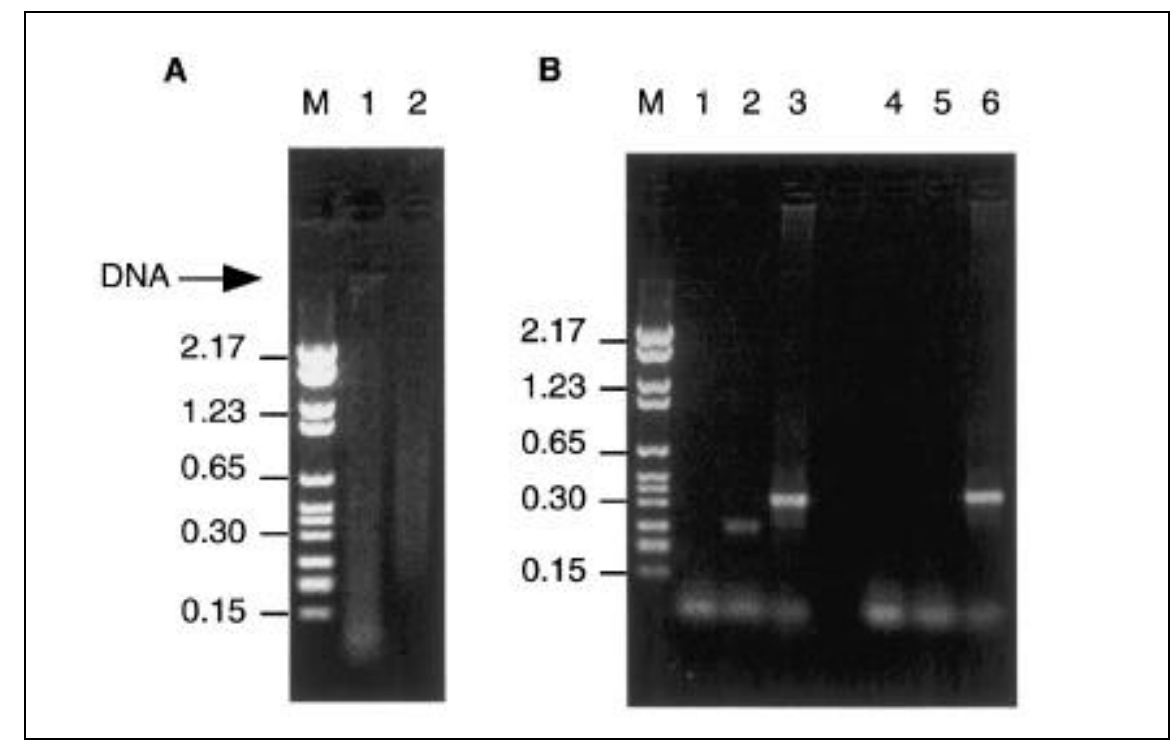

Figure 1. (A) Total RNA from a skin biopsy before (lane 1) and after the centrifugation through a $\mathrm{CsCl}$ cushion (lane 2). Note that not only the residual DNA but also RNA fragments smaller than 150 bp have been removed. $1.5 \mu \mathrm{g}$ (lane 1) and $0.75 \mu \mathrm{g}$ (lane 2) of the total RNA have been loaded. M: Boehringer Mannheim marker VI (top to bottom: 2.17, 1.77, 1.23, 1.03, 0.65, 0.52, 0.45, 0.39, 0.3, 0.23/0.22, 0.15 $\mathrm{kb})$. For the sake of clarity, only some fragment sizes are given in the figure. The samples have been loaded on a $1.2 \%$ agarose gel. (B) RT-PCR with total RNA from skin using a crude RNA preparation (lanes 1-3) and CsCl-purified RNA (lanes 4-6). The resulting cDNAs were probed with primers for the rag-1 (lanes 1 and 4) and rag-2 (lanes 2 and 5) genes, which are not expressed in the skin, and the ubiquitously expressed $\beta$ actin gene (lanes 3 and 6 ). The rag- 2 positive band in lane 2 is due to the DNA contained in this preparation, in contrast to the other two genes, the rag-2 primers map to the same exon. The corresponding band is absent in the reaction prepared with $\mathrm{CsCl}$-purified RNA, indicating that this purification method removes DNA completely from the RNA preparation (lane 5). M: Boehringer Mannheim marker VI. Reverse transcriptase for cDNA synthesis was supplied from New England Biolabs (Beverly, MA, USA) and Taq DNA polymerase was from Boehringer Mannheim. The PCR products have been analyzed on a $2 \%$ agarose gel. 
way still shows some degradation, but was on average much larger than the RNA prepared by conventional methods. Its size ranges from $0.3-2.5 \mathrm{~kb}$ (Figure 1A) and allows for successful RT-PCR. No DNA contamination can be detected after $\mathrm{CsCl}$ purification (Figure 1B).

The high-molecular-weight DNA was processed as described previously (3). The DNA clump was transferred into an Eppendorf vial containing 0.5 $\mathrm{mL}$ of $2 \times$ SET $(150 \mathrm{mM} \mathrm{NaCl}, 5 \mathrm{mM}$ EDTA, $50 \mathrm{mM}$ Tris- $\mathrm{HCl}, \mathrm{pH}$ 8.0) and treated with $50 \mu \mathrm{g} / \mathrm{mL}$ RNase A. RNase A digestion was stopped by the addition of SDS to a final concentration of $0.5 \%$, and the DNA was treated with proteinase $\mathrm{K}(1 \mathrm{mg} / \mathrm{mL}$ final concentration) (Boehringer Mannheim, Mannheim, Germany), until the DNA clump dissolved and became transparent. The DNA was then extracted with phenol/chloroform (1:1, vol/vol) and precipitated with 2.5 volumes of ethanol. To measure the concentration, the DNA was gently sheared and dissolved in TE ( $\mathrm{pH}$ 8.0). On average, 10-15 $\mu \mathrm{g}$ DNA/mg skin tissue were obtained. This yield is roughly five times greater than that of conventional methods (2).

We also tested whether this method is effective for other tissues. For this reason, we treated human culture cells (SeAx), plant leaves (Stachys species), yeast (Saccharomyces cerevisiae) and $E$. coli cells in the same way as described above. The intact bands of the $28 \mathrm{~S}$ and $18 \mathrm{~S}$ rRNA bands and the $23 \mathrm{~S}$ and 16S rRNA bands, respectively, (Figure 2, lanes 1-4) show that the RNA from SeAx cells, Stachys leaves and $E$. coli cells are of good quality. Also high-molecular-weight DNA could be obtained from these tissues and cells in large quantities (Figure 2, lanes 5-8). The RNA from $S$. cerevisiae was partially degraded, and no DNA could be obtained from these cells by the isopropanol precipitation step. Therefore this method is only of limited use for yeast, but it is very suitable for simultaneous RNA and DNA extraction from biopsy material, tissue culture cells, animal and plant tissue and bacterial cells. The possibility to isolate RNA and DNA from biopsy simultaneously, also helps to save significantly material from which mostly only small amounts are available.

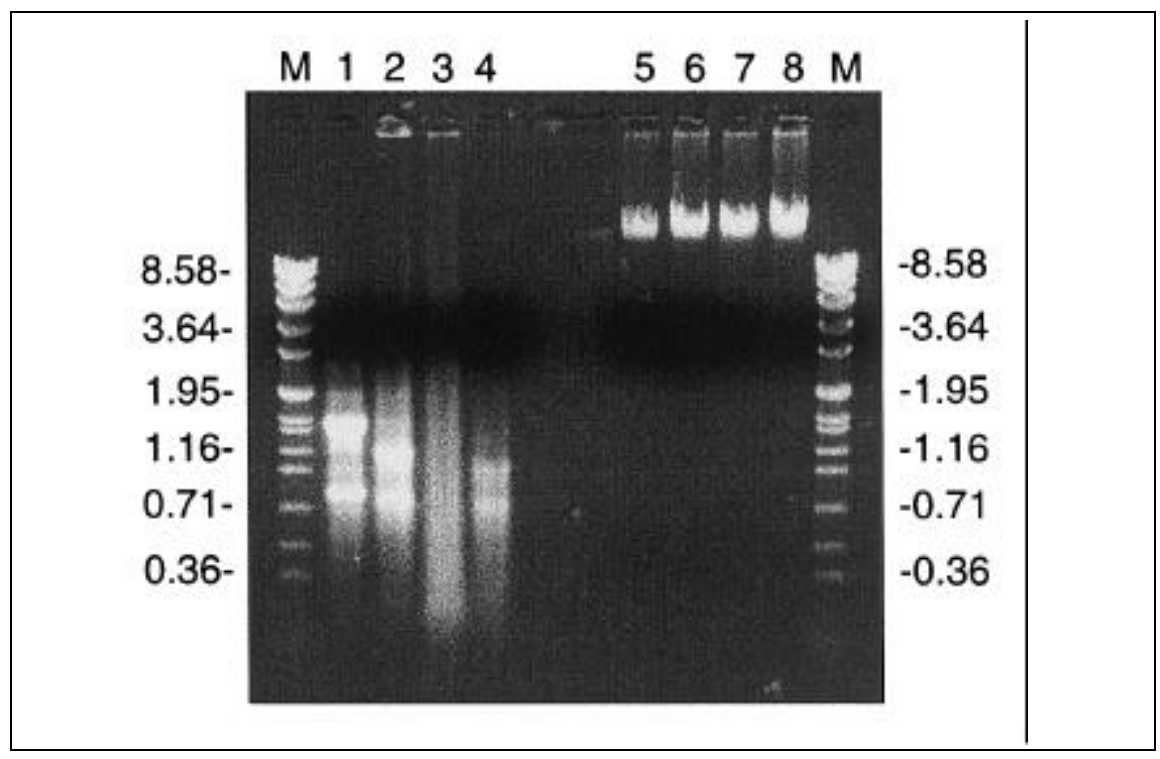

Figure 2. Total RNA (lanes 1-4) and DNA (lanes 5-8) from different tissues and species. Lane 1, SeAx cells (human cutaneous T-cell lymphoma); lane 2, Stachys species (plant); lane 3, S. cerevisiae (yeast); lane 4, E. coli (bacteria); and M, Boehringer Mannheim marker VII. All RNA preparations have been centrifuged through a $\mathrm{CsCl}$ cushion. $1.5 \mu \mathrm{g}$ (lanes 1-3) and $0.75 \mu \mathrm{g}$ (lane 4) of RNA have been loaded. Lane 5, DNA from a skin biopsy; lane 6, DNA from SeAx cells; lane 7, DNA from Stachys species; and lane 8, DNA from E. coli. To avoid retention of high-molecular-weight DNA in the slot, the DNAs of the different samples have been broken up by one run through a QIAshredderTM (Qiagen, Chatsworth, CA, USA). $1.5 \mu \mathrm{g}$ of each DNA have been loaded. The nucleic acids have been analyzed on a 1.0\% agarose gel. For clarity only, the sizes of the most important marker bands are given.

\section{REFERENCES}

1.Glisin, V., R. Crkvenjakov and C. Byus. 1974. Ribonucleic acid isolated by cesium chloride centrifugation. Biochemistry 13: 2633.

2.Sambrook, J., E.F. Fritsch and T. Maniatis. 1989. Molecular Cloning: A Laboratory Manual, 2nd ed. Cold Spring Harbor Laboratory Press, Cold Spring Harbor, NY.

3.Schorpp, M., U. Döbbeling, U. Wagner and G.U. Ryffel. 1988. 5' flanking and 5' proximal exon regions of the two Xenopus albumin genes. Deletion analysis of constitutive promoter function. J. Mol. Biol. 199:83-93.

Address correspondence to Udo Döbbeling, Department of Dermatology, University Hospital Zurich, Gloriastrasse 31, CH-8091 Zurich, Switzerland

Received 15 March 1996; accepted 10 July 1996.

U. Döbbeling, R. Böni, A. Häffner, R. Dummer and G. Burg University Hospital Zurich Zurich, Switzerland 